\title{
Primary malignant fibrous histiocytoma of the breast: report of one case
}

This article was published in the following Dove Press journal:

OncoTargets and Therapy

2 April 2013

Number of times this article has been viewed

\section{Caigang Liu' \\ Zuowei Zhao' \\ Qingfu Zhang² \\ Yunfei $\mathrm{Wu}^{3}$ \\ Feng Jin ${ }^{3}$}

'Department of Breast Surgery,

Second Hospital of Dalian Medical

University, Dalian, People's Republic of

China; ${ }^{2}$ Department of Pathology, First Hospital of China Medical University,

Shenyang, People's Republic of China;

${ }^{3}$ Department of Breast Surgery,

General Surgery, First Hospital of

China Medical University, Shenyang,

People's Republic of China.
Correspondence: Zuowei Zhao Department of Breast Surgery, Second Hospital of Dalian Medical University, Dalian, People's Republic of China

Tel $+8624 I 5940502858$

Fax +862422834060

Email zuoweizhao@163.com

\begin{abstract}
Seven years ago, a 48-year-old female patient discovered a painless tumor in her right breast simply by chance. In the next year, the tumor increased significantly in size. At this point, the patient received a tumor resection, which was misdiagnosed as a benign mesenchymal tissueoriginated tumor. Unfortunately, the tumor recurred just 10 days after resection. We subsequently resected the recurrent lesion and confirmed primary breast malignant fibrous histiocytoma. The tumor began to exhibit an unprecedented, massive, and uncontrolled growth, ulcerating soon after the operation. Treatment of the patient was limited by time. After the patient received a cycle of chemotherapy, she died of cachexia with the emergence of multiorgan metastasis 2 months after the operation.
\end{abstract}

Keywords: breast, primary malignant fibrous histiocytoma, treatment, survival

\section{Introduction}

Malignant fibrous histiocytoma (MFH) is a type of sarcoma characterized by a high degree of malignant neoplasm. Its origin is uncertain and arises in both soft tissue and bone. It typically affects middle-aged females (mean age of 57 years), and rarely affects more elderly males (mean age of 67 years). ${ }^{1,2}$ MFH usually occurs in the limbs, trunk, retroperitoneum, bone, and head and neck, with breast primary MFH being very rare. Patients often complain that a mass or lump has appeared over a short period of time, ranging from weeks to months. The mass does not usually cause pain unless it is compressing a nearby nerve. Symptoms such as weight loss and fatigue are not typical, but can present in patients if the disease has advanced. ${ }^{3-5}$ The literature has reported that primary breast MFH has an average size of $6 \mathrm{~cm}$ and a variable clinical presentation. It can grow slowly or rapidly and is sometimes a painful mass. MFH has also shown invasive growth and a large range of growth speed. The disease usually metastasizes through the blood and lymph nodes; ${ }^{6}$ however, primary breast MFH is rare, and its clinical and pathological diagnosis is very difficult due to its complex and various histological manifestations.

\section{Case report}

Seven years ago, a 48-year-old female patient discovered a $0.8 \mathrm{~cm} \times 0.6 \mathrm{~cm}$ painless tumor in the upper, outer quadrant of her right breast simply by chance. No special treatment was undertaken. She had neither a significant past medical histology, nor a history of family tumors. In the next year, the tumor began to grow significantly, increasing suddenly to a $5 \mathrm{~cm} \times 4 \mathrm{~cm}$ mass, but none of her axillary lymph nodes appeared to be swollen. At this point, the patient received a tumor resection, which was diagnosed pathologically as a 
benign mesenchymal tissue-originated tumor. Unfortunately, another $1.0 \mathrm{~cm} \times 0.8 \mathrm{~cm}$ tumor was discovered 7 months after the first operation, again in the upper, outer quadrant of her right breast. The tumor again increased rapidly from $1.0 \mathrm{~cm} \times 0.8 \mathrm{~cm}$ to $7 \mathrm{~cm} \times 6 \mathrm{~cm}$ within a single month. A physical examination revealed a tumor with poor tumor activity, a less well-defined border, a less smooth surface, and a skin adhesion. Moreover, hard, swollen lymph nodes were felt in the axilla, within the supraclavicular area, and in the neck. Breast skin at the tumor projection area showed local redness, but no nipple dents. Furthermore, the patient's lung and heart physical examinations as well as her laboratory results were normal.

A hypoechoic and irregularly shaped mass, measuring approximately $7 \mathrm{~cm} \times 6 \mathrm{~cm}$ (Figure 1), was found at the edge of the skin incision scar from the previous tumor resection on the right side of the breast. No significant findings were observed in the chest X-ray or the spleen, liver, and gallbladder ultrasound examinations. No evidence of metastasis was observed in the distant organs. We subsequently resected the tumor and found a solid lesion measuring approximately $7 \mathrm{~cm} \times 6 \mathrm{~cm}$ in the upper, outer quadrant of the right breast that had invaded the pectoralis. Grossly, the tumors were white nodules mixed with a sallow composition, presented with a burr-like boundary, no capsule, a brittle texture, and a fish meat-like quality. Formalin-fixed, paraffin-embedded tissue from the resected specimen was obtained for routine microscopic examination and for immunophenotyping of the neoplasm. Specimens were stained with hematoxylin and eosin. Microscopically, the boundaries between the tumor tissues and the surrounding breast tissue were clear, but no fibrous capsule tumor tissue was fragmented by the necrotic tissue chip.

The tumor cells were round or polygonal, and presented with vesicular cytoplasmic and prominent nucleoli, or

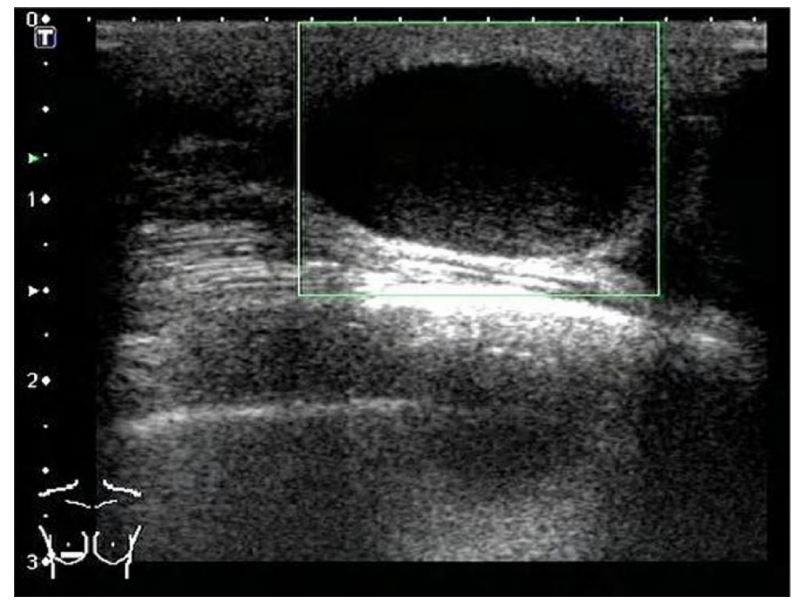

Figure I A regular-shaped mass in the right breast in the ultrasound test. sometimes double nucleoli. The tumor cells were also of large nucleus-stained irregular shapes that were atypical, but were obviously tissue-like cells. Tumor cells were arranged as a knit fabric in some areas, which were composed by myofibroblast- or myofibroblast-like cells (Figure 2). Following these findings, we resected the right breast and pectoralis. Immunohistochemical staining was performed using the streptavidin-biotin peroxidase method. Immunohistochemically, the tumor cells were positive for vimentin, $\alpha 1$-antichymotrypsin, $\alpha 1$-antitrypsin, CD68, $\mathrm{Ki} 67$, and CD34. The cells were negative for creatine kinase, B cell lymphoma/leukemia-2, estrogen receptor, desmin, and mouse antiendomysial antibody (Figure 2). Finally, the tumor was diagnosed as MFH.

The tumor recurred just 10 days after surgery. A $0.8 \mathrm{~cm} \times 0.6 \mathrm{~cm}$ mass with a hard texture was found around the surgical incisions, and in the subsequent 20 days, the tumor grew to $5 \mathrm{~cm} \times 4 \mathrm{~cm}$. At this point, a chest ultrasound was completed. Multiple hypoechoic nodules were seen in the right chest wall, with the largest located in the center with a size of $4.73 \mathrm{~cm} \times 3.56 \mathrm{~cm}$. This nodule was lobulated, had an echogenic periphery, and had rich blood flow. Moreover, swollen axillary lymph nodes were also found in both axilla and the neck, with the largest being $2.51 \mathrm{~cm} \times 0.81 \mathrm{~cm}$. Enhanced computed tomography scanning showed multiple small lung nodules; thus, metastases could not be excluded (Figure 3). The patient received a cycle of CHOP chemotherapy (cyclophosphamide, doxorubicin, vincristine, and prednisone), but the tumor progressed rapidly and eventually ulcerated. With the emergence of multiorgan metastasis, the patient died of multiple distant metastases (Figure 4).

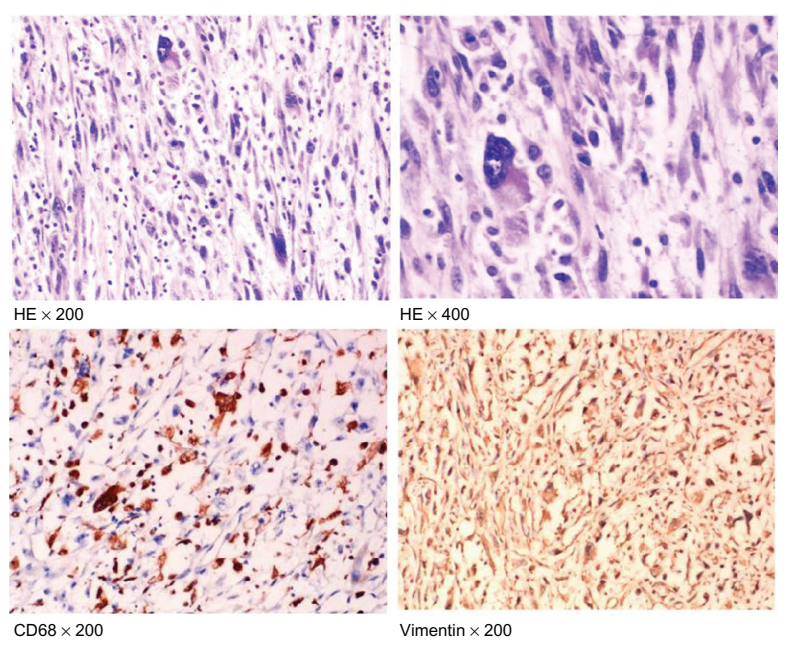

Figure 2 HE staining showing tumor cells with CD68 and vimentin-positive expression $(\times 200$ and $\times 400)$.

Abbreviation: HE, hematoxylin-eosin. 


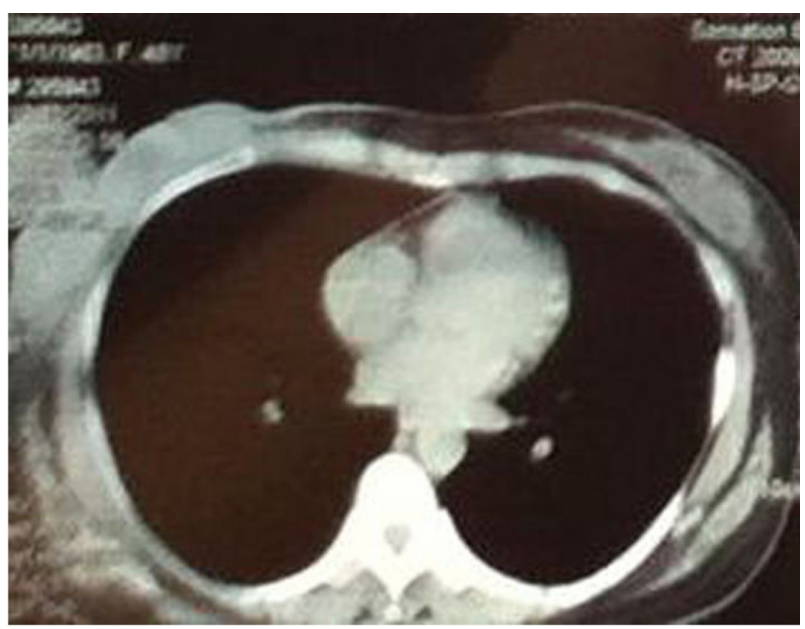

Figure 3 Enhanced computed tomography scanning showed lung metastases.

\section{Discussion}

The origin of MFH is still controversial, ${ }^{7-9}$ with three existing theories dominating: (1) tissue cell origin; (2) fibroblast cell origin; and (3) primitive mesenchymal cell origin. Most oncologists believe that MFH is an intermediate type, and is variant cell-derived from primitive mesenchymal cells that grow during the process of tissue cell and fibroblast

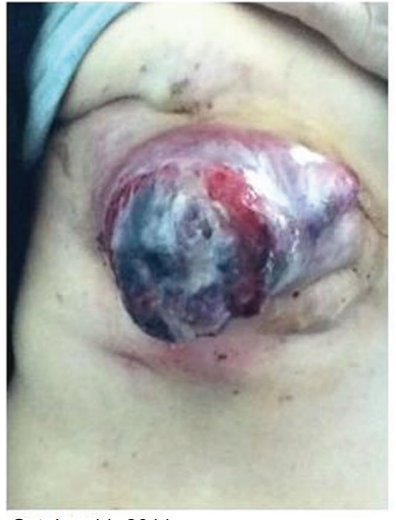

October 11, 2011

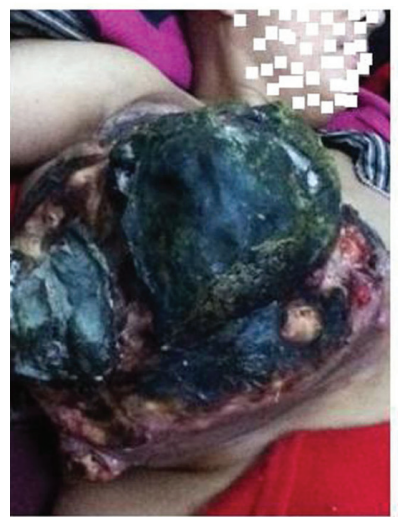

December 4, 2011

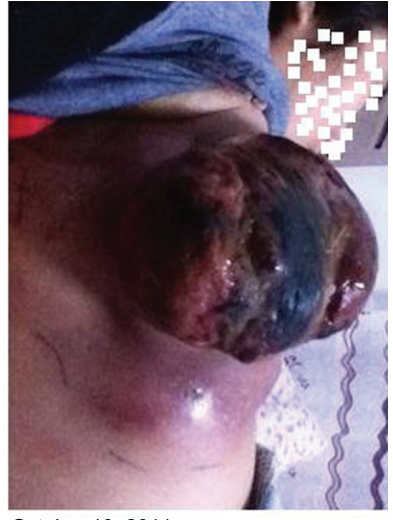

October 19, 2011

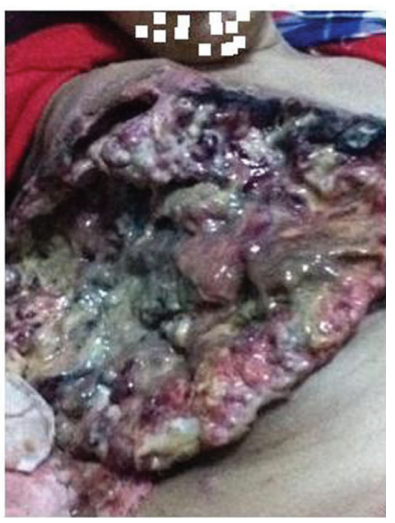

December 16, 2011
Figure 4 Tumor images after surgery. cell differentiation. The diversity of clinical manifestations reflects the various differentiation stages of the primitive mesenchymal cells. Other studies confirmed that mesenchymal cells have some important biological characteristics of tissue cells and fibroblast cells. ${ }^{7-9}$

According to the main morphological characteristics of tumor cells, MFH can be grouped into five types. ${ }^{1,5}$ First is the pleomorphic type, where the most prominent morphological features include the fact that the tumor cells are pleomorphic and have a spoke wheel-like structure, showing spindle cells arranged in spoke wheel shapes. A large number of giant cells are stained with a strongly eosinophilic cytoplasm, and single or multiple irregular nuclei are present in the multishaped area. Inflammatory cells in the tumor tissue, including lymphocytes, plasma cells, and eosinophils, are often mixed with the tumor cells; sometimes, focal ossification or cartilage formation is observed in some MFH tumors. The second type is the myxoid type, where the rare tumor cells are round- or star-shaped and scattered in the loose mucus matrix. The myxoid type occupies more than $50 \%$ of the area. Vacuoles can be seen within the cytoplasm of the tumor cells, which are similar to the lipoblastoma cells, but special staining shows acidic mucus in the vacuoles. Third is yellow tumor or inflammatory type. The most prominent feature of this type is a large number of foamy yellow tumor cells in various differentiations mixed with a large number of inflammatory cells, particularly neutrophilic granulocytes. The yellow tumor cells might congregate or be distributed diffusely. On the other hand, sometimes poorly differentiated tumor cells have little cytoplasm and large nuclei, and mitotic activity is usually visible. Spindle fibroblast proliferation, spoke wheel-like structures, and necrosis are also common. Fourth is the giant tumor cell type. Here, the tumor is nodular and is formed by the fibroblasts, histiocytes, and spread osteoclast-type giant cells. Some tumors present as malignant, giant tumor cells with frequent mitotic activity. The tumors are usually hemorrhaging, exhibit necrosis, and sometimes present with bone-like tissue or mature bone tissue. Fifth is the hemangioma-like type, where the tumor tissue is formed by irregular solid tissue cells, irregular lacunar cells caused by irregular bleeding, and chronic inflammatory cell infiltration. With this type, lymphoid follicles are often formed in the tumor periphery.

Some tumors can be distinguished from MFH, including malignant phyllodes tumors, malignant myoepithelioma, and myofibroblastic tumors. ${ }^{10-14}$ The intercellular substances of the malignant phyllodes tumors usually have fibrosarcomalike changes with bidirectional differentiation. The structure 
of the epithelial remnants can be identified from MFH. ${ }^{10}$ Malignant myoepithelioma is composed mainly of spindle cells, which present in an invasive growth pattern. The tumor cells positively express P63, smooth-muscle actin (SMA), $34 \beta$, and E12. ${ }^{11}$ Malignant myoepithelioma has a variety of cell morphologies with obvious atypia; here, SMAnegative can be identified from MFH. MFH should also be distinguished from myofibroblastic tumors. Myofibroblastic tumors usually have capsules, with a clear boundary, and are rarely necrotic and mitotic. The only similarity is that vimentin, desmin, and SMA are also often positively expressed in myofibroblastic tumors. ${ }^{12,14}$ For the mesenchymal breast tumor, phyllodes tumor and metaplastic carcinoma should be considered first. ${ }^{14}$

Surgery is the cornerstone of treatment for all soft tissue sarcomas. The goal of surgery is to eradicate all of the disease in the affected area. Although the case reported here included performing three surgical tumor resections, the tumor featured rapid disease progression, subsequent relapse, and metastasis. The patient ultimately died of lung metastasis. For MFH, the role of chemotherapy in treatment is not entirely clear. ${ }^{1}$ Several clinical trials incorporating the chemotherapy drug doxorubicin have shown improved event-free survival without a major impact on overall survival. ${ }^{15}$ Radiation clearly improves the incidence of local recurrence and has become an integral part of the treatment for MFH. ${ }^{16,17}$ Some factors, however, contribute to the poor prognosis of $\mathrm{MFH}$, including a lack of molecular targets for $\mathrm{MFH}$ treatment.

\section{Conclusion}

The clinical manifestations of MFH vary widely, and most surgeons do not have much experience in diagnosing the disease. This results in a long diagnostic period. As such, some patients lose the chance to receive early treatment. Therefore, the study of the clinical manifestations and the pathological roles of MFH have become important in understanding the disease. When possible, exploiting effective treatment is also important.

\section{Acknowledgments}

This study was supported by the grant from the China National Natural Science Foundation (No 81102029 and 81172047).

\section{Disclosure}

The authors report no conflicts of interest in this work.

\section{References}

1. Hartel PH, Bratthauer G, Hartel JV, Fanburg-Smith JC. Primary malignant fibrous histiocytoma (myxofibrosarcoma/pleomorphic sarcoma not otherwise specified) of the breast: clinicopathologic study of 19 cases. Ann Diagn Pathol. 2011;15(6):407-413.

2. Bilici S, Yigit O, Taskin U, Gucin Z. Recurrence of a simultaneous tumor of the parotid gland and scalp skin malignant fibrous histiocytoma. J Craniofac Surg. 2011;22(5):1898-1999.

3. Elmas E, Kälsch T, Borggrefe M, Haghi D. A mobile structure at the entrance of the left atrial appendage in a patient with malignant fibrous histiocytoma. Anadolu Kardiyol Derg. 2011;11(8):741-742.

4. Joshi H, Rayappa CS. Malignant fibrous histiocytoma of the mandible and the infratemporal fossa-A case report. Int J Surg Case Rep. 2011; 2(6):134-137.

5. Katsourakis A, Noussios G, Hadjis I, Evangelou N, Chatzitheoklitos E. Primary malignant fibrous histiocytoma: a rare case. Case Rep Med. 2011;2011:134801.

6. Mahalingam SB, Mahalingam K, McDonough S. Malignant fibrous histiocytoma in a male breast: a case report. J Clin Oncol. 2011;29(24):e682-e684.

7. Falidas E, Rallis E, Ntatsi A, Mathioulakis S, Villias C. Malignant fibrous histiocytoma masquerading as gluteal abscess. $J$ Cutan Med Surg. 2011;15(6):354-355.

8. Kano M, Tsukahara T, Emori M, et al. Autologous CTL response against cancer stem-like cells/cancer-initiating cells of bone malignant fibrous histiocytoma. Cancer Sci. 2011;102(8):1443-1447.

9. Pobirci DD, Bogdan F, Pobirci O, Petcu CA, Roşca E. Study of malignant fibrous histiocytoma: clinical, statistic and histopatological interrelation. Rom J Morphol Embryol. 2011;52(Suppl 1):385-388.

10. Swapp RE, Shon W, Peethambaram PP, Moran SL, Reynolds C. Cutaneous presentation of a distant metastasis of malignant phyllodes tumor. Int J Dermatol. 2012;51(1):72-74.

11. Terada T. Malignant myoepithelioma of the breast. Pathol Int. 2011; 61(2):99-103.

12. Fragoso AC, Eloy C, Estevão-Costa J, Campos M, Farinha N, Lopes JM. Abdominal inflammatory myofibroblastic tumor a clinicopathologic study with reappraisal of biologic behavior. J Pediatr Surg. 2011;46(11):2076-2082.

13. Kanda S, Koizumi T, Kobayashi N, Kubo K. Oropharyngeal metastasis of cardiogenic angiosarcoma. Intern Med. 2012;51(1):127-128.

14. Kashima K, Yamashita E, Mataki H, et al. Primary leiomyosarcoma of the pulmonary artery: a case of a 20-month survivor after incomplete surgical resection. Intern Med. 2012;51(1):75-78.

15. Adjuvant chemotherapy for localised resectable soft-tissue sarcoma of adults: meta-analysis of individual data. Sarcoma Meta-analysis Collaboration. Lancet. 1997;350(9092):1647-1654.

16. Barkley HT Jr, Martin RG, Romsdahl MM, Lindberg R, Zagars GK. Treatment of soft tissue sarcomas by preoperative irradiation and conservative surgical resection. Int J Radiat Oncol Biol Phys. 1988;14(4):693-699.

17. Lindberg RD, Martin RG, Romsdahl MM, Barkley HT Jr. Conservative surgery and postoperative radiotherapy in 300 adults with soft-tissue sarcomas. Cancer. 1981;47(10):2391-2397. 
OncoTargets and Therapy

\section{Publish your work in this journal}

OncoTargets and Therapy is an international, peer-reviewed, open access journal focusing on the pathological basis of all cancers, potential targets for therapy and treatment protocols employed to improve the management of cancer patients. The journal also focuses on the impact of management programs and new therapeutic agents and protocols on

patient perspectives such as quality of life, adherence and satisfaction. The manuscript management system is completely online and includes a very quick and fair peer-review system, which is all easy to use. Visit http://www.dovepress.com/testimonials.php to read real quotes from published authors.

Submit your manuscript here: http://www.dovepress.com/oncotargets-and-therapy-journal 